\title{
Implication of PHF2 Expression in Clear Cell Renal Cell Carcinoma
}

\author{
Cheol Lee ${ }^{1} \cdot$ Bohyun Kim ${ }^{1}$ \\ Boram Song ${ }^{1} \cdot$ Kyung Chul Moon ${ }^{1,2}$ \\ 'Department of Pathology, Seoul National \\ University College of Medicine, Seoul; \\ ${ }^{2}$ Kidney Research Institute, Medical Research \\ Center, Seoul National University College of \\ Medicine, Seoul, Korea \\ Received: February 9, 2017 \\ Revised: March 8, 2017 \\ Accepted: March 14, 2017

\section{Corresponding Author} \\ Kyung Chul Moon, MD \\ Department of Pathology, Kidney Research Institute, \\ Medical Research Center, Seoul National University \\ College of Medicine, 103 Daehak-ro, Jongno-gu, \\ Seoul 03080, Korea \\ Tel: +82-2-2072-1767 \\ Fax: +82-2-743-5530 \\ E-mail: blue7270@snu.ac.kr
}

\begin{abstract}
Background: Clear cell renal cell carcinoma (CCRCC) is presumed to be associated with adipogenic differentiation. Histone modification is known to be important for adipogenesis, and the function of histone demethylase plant homeodomain finger 2 (PHF2) has been noted. In addition, PHF2 may act as a tumor suppressor via epigenetic regulation of p53 and is reported to be reduced in colon cancer and stomach cancer tissues. In this study, we examined PHF2 expression in CCRCC specimens by immunohistochemistry. Methods: We studied 254 CCRCCs and 56 non-neoplastic renal tissues from patients who underwent radical or partial nephrectomy between 2000 and 2003 at the Seoul National University Hospital. Tissue microarray blocks were prepared, and immunohistochemical staining for PHF2 was performed. Results: Among 254 CCRCC cases, 150 cases (59.1\%) showed high expression and 104 cases (40.1\%) showed low expression. High expression of PHF2 was significantly correlated with a low Fuhrman nuclear grade $(p<.001)$, smaller tumor size $(p<.001)$, low overall stage $(p=.003)$, longer cancer-specific survival $(p=.002)$, and progression-free survival $(p<.001)$ of the patients. However, it was not an independent prognostic factor in multivariate analysis adjusted for Fuhrman nuclear grade and overall stage. Conclusions: Our study showed that low expression of PHF2 is associated with aggressiveness and poor prognosis of CCRCC.
\end{abstract}

Key Words: PHF2 protein, human; Carcinoma, renal cell; Clear cell renal cell carcinoma; Immunohistochemistry; Adipogenesis
Renal cancer is one of the most common cancers in Korean males. ${ }^{1}$ Among the types of renal cancer, clear cell renal cell carcinoma (CCRCC) is the most common. CCRCC can exhibit various histologic features, ${ }^{2}$ but most tumors are golden yellow due to the abundant lipid contents of the cells, and microscopically, the tumor cells have a clear cytoplasm similar to adipocytes. ${ }^{3}$ The tumor cells have abundant cytoplasmic lipids in addition to glycogen, as revealed by an ultrastructural study. ${ }^{4}$ For this reason, CCRCC is presumed to be associated with adipogenic differentiation. Until recently, although three studies have shown that CCRCC is associated with adipogenic differentiation, ${ }^{5-7}$ the association of tumorigenesis with clear cell morphology is still required at the molecular level.

In recent studies, histone modification has been confirmed to be important in adipogenesis. In particular, the function of histone demethylase plant homeodomain finger 2 (PHF2), as it maps to human chromosome 9q22, has been noted. ${ }^{9,10}$ PHF2 is a dimethylated histone $\mathrm{H} 3$ lysine $9(\mathrm{H} 3 \mathrm{~K} 9 \mathrm{me} 2)$ demethylase ${ }^{10}$ that acts both in gluconeogenesis of hepatocytes and in signaling for regulation of immune and homeogenesis of macrophages in vitro. ${ }^{11,12}$

The physiological role of PHF2 in vivo is not yet clear, but it may be a co-activator with multiple transcription factors. ${ }^{10}$ To the best of our knowledge, only a few studies have investigated the association of PHF2 expression with human cancers, such as breast cancer, esophageal cancer and squamous cell carcinoma of the head and neck. ${ }^{13-15}$ A recent study has shown that PHF2 can act as a tumor suppressor through epigenetic regulation of $\mathrm{p} 53$ and shows reduced expression in colon cancer and stomach cancer tissues. ${ }^{16}$ However, there has been no report of PHF2 expression in CCRCC.

In this study, we investigated the relationship between the expression level of PHF2 and clinicopathological factors and prognosis in CCRCC patients using immunohistochemical staining of CCRCC specimens.

\section{MATERIALS AND METHODS}

\section{Patients and tissue microarray}

We examined 254 CCRCCs and 56 non-neoplastic renal tissues including the cortex and medulla from patients who underwent radical or partial nephrectomy between 2000 and 2003 in Seoul National University Hospital. Tissue microarray (TMA) blocks 
containing representative tumor and non-neoplastic tissue core sections (2 $\mathrm{mm}$ in diameter) were prepared from each formalinfixed paraffin block (SuperBioChips Laboratories, Seoul, Korea). All available hematoxylin and eosin-stained slides were reviewed to assess the validity of the diagnosis, and tumors were graded from 1 to 4 according to the Fuhrman nuclear grade system. Clinical and pathological information was collected from electronic medical records and pathological reports. The follow-up period ranged from 2 to 163 months, and the median follow-up period was 84.5 months. This study was approved by Seoul National University Hospital's Institutional Review Board (IRB).

\section{Immunohistochemistry}

Immunohistochemical staining for PHF2 was performed on $4 \mu \mathrm{m}$-thick sections taken from TMA. Immunohistochemistry (IHC) was performed using the Ventana Benchmark XT automated dyeing system (Ventana Medical Systems, Tucson, AZ, USA). Polyclonal rabbit anti-PHF2 antibody (Novus Biologicals,
Littleton, CO, USA) was diluted 1:200. Immunohistochemically stained TMA slides were individually reviewed by two pathologists without clinicopathological information.

In non-neoplastic renal tissue, PHF2 was commonly expressed in the nucleus and cytoplasm of the proximal tubular epithelium, but only in the nucleus of the distal tubular epithelium and podocytes of the glomerulus (Fig. 1). The expression of PHF2 was assessed in both the nucleus and cytoplasm of CCRCCs and classified as high when nuclear expression was observed in more than $10 \%$ of the tumor cells, regardless of cytoplasmic expression (Fig. 2).

\section{Statistical analysis}

Statistical analysis was performed using the statistical program SPSS ver. 21.0 (IBM Corp., Armonk, NY, USA). The chisquared test was used to analyze the relationship between PHF2 expression and clinicopathological characteristics. Survival curves were generated using the Kaplan-Meier method, and survival rate differences were compared using the log-rank test.
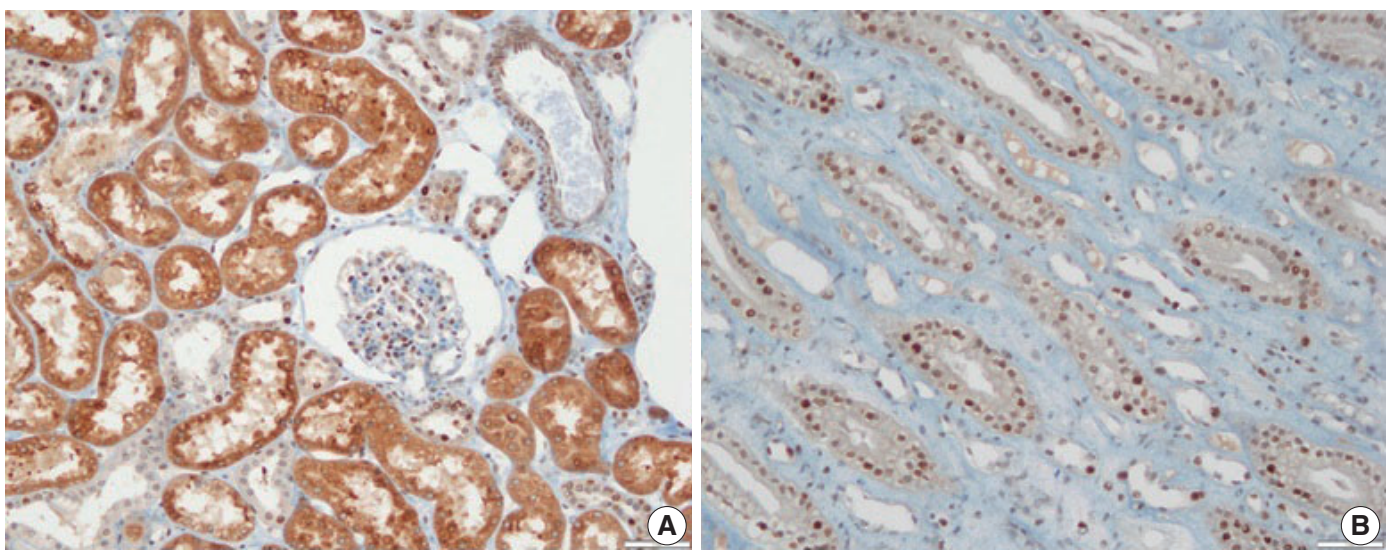

Fig. 1. Plant homeodomain finger 2 (PHF2) expression in non-neoplastic renal tissue. PHF2 is expressed in the nucleus and cytoplasm of the proximal tubular epithelium and in the nucleus of the distal tubular epithelium and podocytes in the glomerulus. (A) Cortex. (B) Medulla.
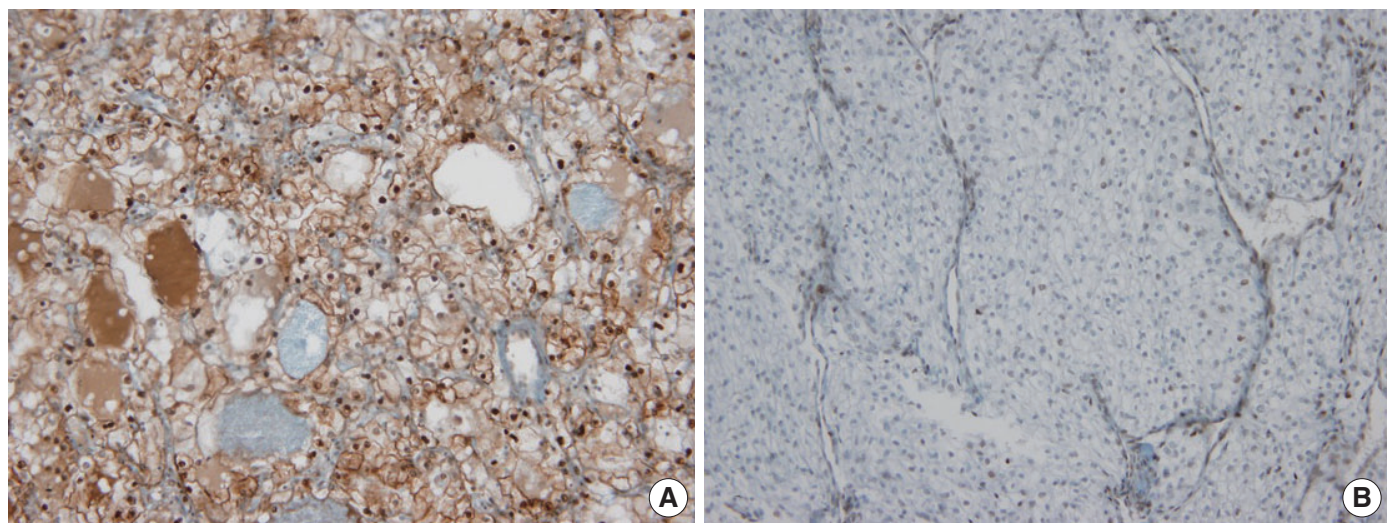

Fig. 2. Plant homeodomain finger 2 expression in clear cell renal cell carcinoma. (A) High expression (B) Low expression. 
The multivariate Cox proportional hazard model was used to analyze the importance of various variables for survival. p-values less than .05 were considered statistically significant.

\section{RESULTS}

\section{Basic clinicopathological characteristics}

Of the 254 patients in this study, 187 (73.6\%) were males and $67(26.4 \%)$ were females. The age at diagnosis was between 28 and 82 years old. The mean age \pm standard deviation (SD) and median age were $56.2 \pm 11.3$ years and 57 years, respectively. We have classified them into two groups: older than 57 years or not. The Fuhrman nuclear grade distribution was 16 cases in grade I (6.3\%), 113 cases in grade II (44.5\%), 93 cases in grade III $(36.6 \%)$, and 32 cases in grade IV (12.6\%). The tumor size ranged from 1.0 to $22.0 \mathrm{~cm}$ and the mean $\pm \mathrm{SD}$ size was $5.6 \pm 3.5$ $\mathrm{cm}$. At the time of diagnosis, 23 patients (9.1\%) had metastatic cancers and 231 (90.9\%) did not. According to the prognostic classification of the American Joint Committee on Cancer 7th edition, ${ }^{17}$ the $\mathrm{T}$ stage was as follows: T1 was 164 cases (64.6\%), T2 was 38 cases (15.0\%), T3 was 50 cases (19.7\%), and T4 was

Table 1. Relationship between PHF2 expression and clinicopathological characteristics

\begin{tabular}{|c|c|c|c|c|}
\hline \multirow[b]{2}{*}{ Characteristic } & \multirow[b]{2}{*}{$\begin{array}{l}\text { No. of } \\
\text { cases } \\
(n=254)\end{array}$} & \multicolumn{2}{|c|}{ PHF2 expression } & \multirow[b]{2}{*}{$p$-value } \\
\hline & & $\begin{array}{c}\text { Low } \\
(n=104, \\
40.1 \%)\end{array}$ & $\begin{array}{c}\text { High } \\
(n=150 \\
59.1 \%)\end{array}$ & \\
\hline Age (yr) & & & & .006 \\
\hline$<57$ & $124(48.8)$ & 40 & 84 & \\
\hline$\geq 57$ & $130(51.2)$ & 64 & 66 & \\
\hline Sex & & & & .320 \\
\hline Male & $187(73.6)$ & 80 & 107 & \\
\hline Female & $67(26.4)$ & 24 & 43 & \\
\hline Fuhrman grade & & & & $<.001$ \\
\hline 1,2 & $129(50.8)$ & 38 & 91 & \\
\hline 3,4 & $125(49.2)$ & 66 & 59 & \\
\hline Tumor size $(\mathrm{cm})$ & & & & $<.001$ \\
\hline$<5$ & $145(57.1)$ & 44 & 101 & \\
\hline$\geq 5$ & $109(42.9)$ & 60 & 49 & \\
\hline T stage & & & & .071 \\
\hline 1,2 & $202(79.5)$ & 77 & 125 & \\
\hline 3,4 & $52(20.5)$ & 27 & 25 & \\
\hline Metastasis at diagnosis & & & & .111 \\
\hline No & $231(90.9)$ & 91 & 140 & \\
\hline Yes & $23(9.1)$ & 13 & 10 & \\
\hline Overall stage & & & & .003 \\
\hline I, I| & $193(76.0)$ & 69 & 124 & \\
\hline III, IV & $61(24.0)$ & 35 & 26 & \\
\hline
\end{tabular}

Values are presented as number (\%). PHF2, plant homeodomain finger 2. two cases $(0.8 \%)$. Additionally, the overall stage was 162 cases in stage I $(63.8 \%), 31$ cases in stage II $(12.2 \%), 37$ cases in stage III (14.6\%), and 24 cases in stage IV (9.4\%) (Table 1).

\section{Immunohistochemical result of PHF2 and relationship with} clinicopathological characteristics

Of the 254 cases, 150 cases (59.1\%) showed high expression, and 104 cases (40.1\%) showed low expression. The high expression of PHF2 was associated with a younger age group ( $\mathrm{p}=.006)$ and significantly correlated with low Fuhrman nuclear grade, small tumor size and low overall stage $(\mathrm{p}<.001, \mathrm{p}<.001$, and $\mathrm{p}=$ .003 , respectively) (Table 1). However, there was no association with the patients' sex, T stage, or metastasis at diagnosis.

\section{The association between PHF2 expression and survival time of the patients}

To assess prognostic value, we evaluated the association between PHF2 expression and patient survival by a log-rank test using Kaplan-Meier analysis. We observed that high expression of PHF2 was significantly associated with longer cancer-specific survival $(\mathrm{p}=.002)$ and progression-free survival $(\mathrm{p}<.001)$ in CCRCC patients (Fig. 3).

\section{Univariate and multivariate Cox regression analysis of cancer-specific survival and progression-free survival}

Univariate cox regression analysis showed significant correlation with age (less than 57 or not), Fuhrman nuclear grade, tumor size (less than $5 \mathrm{~cm}$ or not), T stage, metastasis at diagnosis, overall stage, PHF2 expression status, cancer-specific survival ( $\mathrm{p}=.009$ for age, $\mathrm{p}=.003$ for PHF2 expression status, and $\mathrm{p}<.001$ for the others), and progression-free survival ( $\mathrm{p}=.001$ for age and $\mathrm{p}$ $<.001$ for the others) (Table 2). However, multivariate analysis adjusted for age, Fuhrman nuclear grade and overall stage showed that high expression of PHF2 was not an independent prognostic factor in CCRCC patients with cancer-specific survival $(\mathrm{p}=.566)$ and progression-free survival $(\mathrm{p}=.099)($ Table 2$)$.

\section{DISCUSSION}

In this study, we analyzed the association of PHF2 expression with other clinicopathological parameters and survival time of the CCRCC patients. High expression of PHF2 was associated with a young age group and correlated significantly with low Fuhrman nuclear grade and overall stage. We also observed that high expression of PHF2 was significantly correlated with longer cancer-specific survival and progression-free survival in patients. 

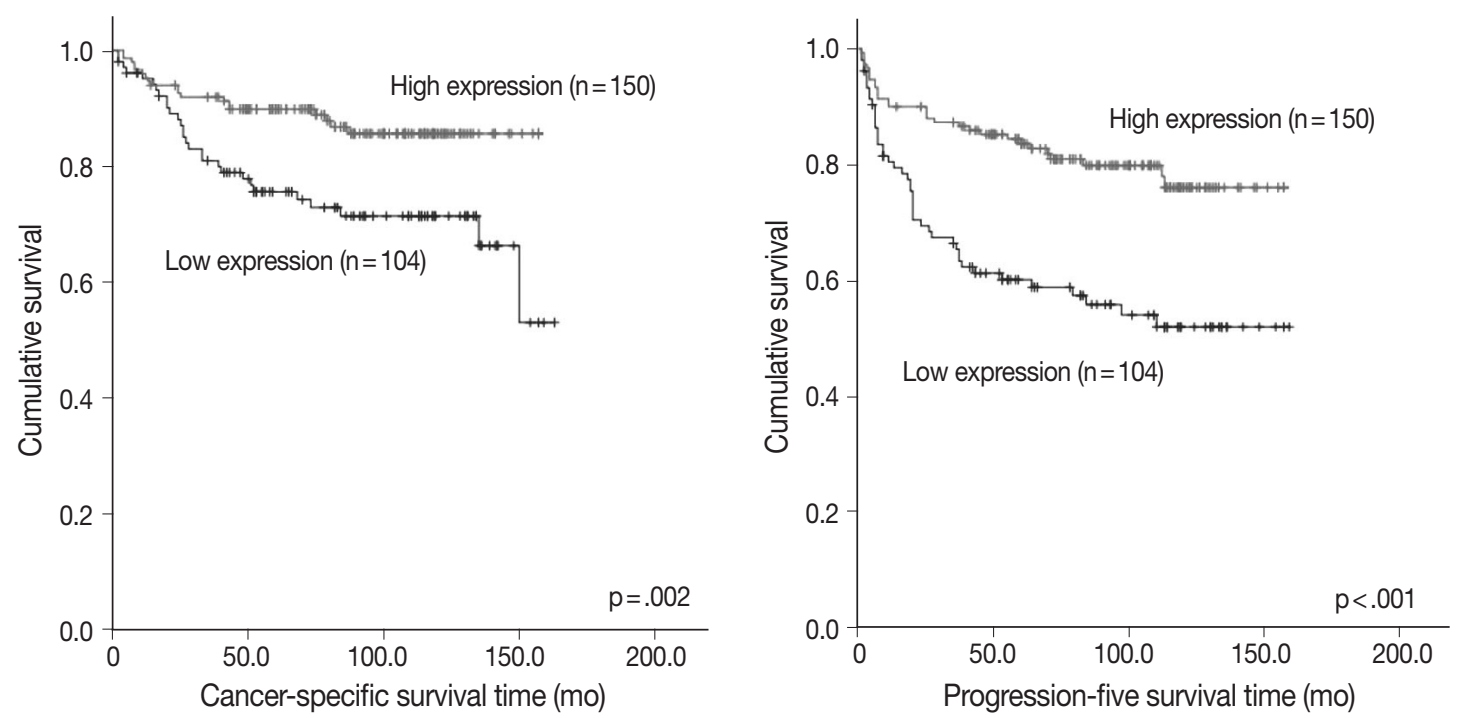

Fig. 3. Kaplan-Meier curves. Cancer-specific and progression-free survival according to plant homeodomain finger 2 (PHF2) expression.

Table 2. Univariate and multivariate Cox regression analysis of cancer-specific and progression-free survival

\begin{tabular}{|c|c|c|c|c|c|c|}
\hline \multirow{2}{*}{ Parameter } & \multicolumn{3}{|c|}{ Univariate analysis } & \multicolumn{3}{|c|}{ Multivariate analysis } \\
\hline & $p$-value & $\mathrm{HR}$ & $95 \% \mathrm{Cl}$ & $p$-value & $\mathrm{HR}$ & $95 \% \mathrm{Cl}$ \\
\hline \multicolumn{7}{|l|}{ Cancer-specific survival } \\
\hline Age (<57 yr vs $\geq 57$ yr) & .009 & 2.239 & $1.227-4.088$ & .393 & 1.312 & $0.704-2.448$ \\
\hline Sex (male vs female) & .870 & 0.947 & $0.492-1.821$ & & & \\
\hline Fuhrman grade $(1,2$ vs 3,4$)$ & $<.001$ & 7.754 & $3.463-17.363$ & $<.001$ & 4.391 & $1.911-10.089$ \\
\hline Tumor size $(<5 \mathrm{~cm}$ vs $\geq 5 \mathrm{~cm})$ & $<.001$ & 8.130 & $3.801-17.391$ & & & \\
\hline T stage $(1,2$ vs 3,4$)$ & $<.001$ & 9.021 & $5.021-16.207$ & & & \\
\hline Metastasis at diagnosis (no vs yes) & $<.001$ & 26.511 & $14.102-49.840$ & & & \\
\hline Overall stage (I, II vs III, IV) & $<.001$ & 15.961 & 8.233-30.945 & $<.001$ & 10.616 & $5.313-21.214$ \\
\hline PHF2 expression (low vs high) & .003 & 0.419 & $0.235-0.749$ & .566 & 0.840 & $0.463-1.524$ \\
\hline \multicolumn{7}{|l|}{ Progression-free survival } \\
\hline Age $(<57$ yr vs $\geq 57$ yr) & .001 & 2.324 & $1.436-3.762$ & .121 & 1.483 & $0.902-2.440$ \\
\hline Sex (male vs female) & .959 & 0.987 & $0.586-1.660$ & & & \\
\hline Fuhrman grade $(1,2$ vs 3,4$)$ & $<.001$ & 3.972 & $2.357-6.692$ & .001 & 2.491 & $1.447-4.287$ \\
\hline Tumor size $(<5 \mathrm{~cm}$ vs $\geq 5 \mathrm{~cm})$ & $<.001$ & 8.416 & $4.692-15.096$ & & & \\
\hline T stage $(1,2$ vs 3,4$)$ & $<.001$ & 6.573 & $4.121-10.484$ & & & \\
\hline Metastasis at diagnosis (no vs yes) & $<.001$ & 19.269 & $11.058-33.578$ & & & \\
\hline Overall stage (I, II vs III, IV) & $<.001$ & 9.230 & $5.744-14.832$ & $<.001$ & 6.470 & $3.933-10.643$ \\
\hline PHF2 expression (low vs high) & $<.001$ & 0.385 & $0.242-0.611$ & .099 & 0.666 & $0.411-1.079$ \\
\hline
\end{tabular}

$\mathrm{HR}$, hazard ratio; $\mathrm{Cl}$, confidence interval.

Multivariate analysis adjusted for age, Fuhrman nuclear grade and overall stage showed that high expression of PHF2 was not an independent prognostic factor for cancer-specific survival and progression-free survival in CCRCC patients.

PHF2 is a type of histone demethylase, and histone modification is known to be important in adipogenesis. ${ }^{9,10,18}$ PHF2 has been shown to play a role in gluconeogenesis in hepatocytes of fasted mice ${ }^{11}$ and proinflammatory gene regulation in macrophages in vitro. ${ }^{12}$ In a recent study, PHF2 was shown to play an important role in adipogenesis in transgenic mice. ${ }^{9}$ PHF2 de- methylates the AT-rich interactive domain-containing protein $5 \mathrm{~B}$ (ARID5B) and binds the promoter regions of target genes by forming a complex with demethylated ARID5B. ${ }^{10,11}$ PHF2 interacts with CCAAT/enhancer-binding protein alpha (CEBPA), one of the major regulators of adipogenesis, and promotes adipogenesis by demethylating $\mathrm{H} 3 \mathrm{~K} 9 \mathrm{me} 2$ in the promoter region of CEBPA target gene. These results indicate that PHF2 promotes adipogenesis by coactivation of CEBPA and that PHF2 is a novel histone methylation-modifying enzyme that modulates adipogenesis. $^{9,10}$ 
As mentioned earlier, some studies have shown that adipogenic differentiation is associated with CCRCC. ${ }^{5-7}$ One study showed that gene expression patterns and IHC results in CCRCC tissues were associated with adipogenesis. ${ }^{7}$ They also found that CCRCC cells undergo adipogenic transdifferentiation, based on the observation that the clear cell morphology of CCRCC cells disappeared in standard cell culture media and was redeveloped in adipogenic media. ${ }^{7}$ This study concluded that adipogenesis was a type of epithelial mesenchymal transition. ${ }^{7}$ Another study has shown that adipose differentiation-related protein (ADFP) expression is increased at both mRNA and protein levels of CCRCC compared to non-neoplastic renal tissues and other types of renal cell carcinoma. ${ }^{5}$ ADFP was originally known as a protein associated with lipid metabolism, highly expressed in adipocytes and variably expressed in other cells. ${ }^{19,20}$ Higher ADFP levels in CCRCC were associated with a lower grade, lower stage and better prognosis, while higher ADFP levels were an independent good prognostic factor in multivariate analysis. ${ }^{5,6}$

In previous studies, CCRCC with low nuclear grade showed a typical clear cell morphology, but CCRCC with a higher nuclear grade showed reduced clear cell morphology and other morphological features that are relatively frequently observed in metastatic renal cell carcinoma, such as eosinophilic cytoplasm and rhabdoid feature. ${ }^{2,21}$ These results suggest that clear cell morphology due to adipogenesis in CCRCC is associated with low nuclear grade and good prognosis. In this regard, our findings suggest that adipogenic differentiation by histone modification is a new tumorigenic mechanism that reflects the clear cell morphology in CCRCC. In addition, the loss of PHF2 expression seems to be correlated with tumor progression and a poor prognosis of CCRCC due to the loss of adipogenic differentiation.

The role of PHF2 in tumorigenesis is not yet well understood, and only a few studies have examined the association between human cancer and PHF2 expression. The expression of PHF2 in breast cancer was not correlated with patient prognosis. ${ }^{13}$ In esophageal squamous cell carcinoma, PHF2 was overexpressed in cancer cells compared to the non-neoplastic epithelium, and high cytoplasmic expression of PHF2 tended to be associated with decreased overall survival of the patients, but there was no statistical significance. ${ }^{14}$ In head and neck squamous cell carcinoma, loss of heterozygosity was observed in the chromosomal 9q22 locus located in the PHF2 gene in relation to dysplastic lesions, but it was not related to the clinicopathological index or patient survival rate. ${ }^{15,22}$

A recent study showed that PHF2 can modulate $\mathrm{p} 53$ by demethylating $\mathrm{H} 3 \mathrm{~K}$ 9me2, and down-regulation of PHF2 expression occurs in colon and stomach cancer. ${ }^{16}$ In the study, they suggested that PHF2 acts as a tumor suppressor by regulating the function of $\mathrm{p} 53 .{ }^{16}$ Even $\mathrm{p} 53$-positive colon cancer cells have a malignant phenotype associated with the suppression of $\mathrm{p} 21$, a downstream molecule of $\mathrm{p} 53 .{ }^{16}$ They also suggested that PHF2 expression levels could help predict patient outcomes in tumors expressing functional $\mathrm{p} 53 .{ }^{16}$ These results provide another perspective on the role of PHF2 in CCRCC, although the role of $\mathrm{p} 53$ in the progression of CCRCC remains controversial. ${ }^{23-25}$

Our study showed the clinicopathological significance of PHF2 expression in CCRCC. Low expression of PHF2 is associated with aggressiveness and poor prognosis of CCRCC, and this effect of PHF2 may be related to the role of PHF2 in adipogenesis or the regulation of $\mathrm{p} 53$. More functional studies will help clarify the role of PHF2 in the development and progression of CCRCC.

\section{Conflicts of Interest}

No potential conflict of interest relevant to this article was reported.

\section{REFERENCES}

1. Jung KW, Won YJ, Kong HJ, Oh CM, Seo HG, Lee JS. Cancer statistics in Korea: incidence, mortality, survival and prevalence in 2010. Cancer Res Treat 2013; 45: 1-14.

2. Lee C, Park JW, Suh JH, Nam KH, Moon KC. Histologic variations and immunohistochemical features of metastatic clear cell renal cell carcinoma. Korean J Pathol 2013; 47: 426-32.

3. Eble JN, Sauter G, Epstein JI, Sesterhenn IA. Pathology and genetics of tumours of the urinary system and male genital organs. Lyon: IARC Press, 2004; 12-39.

4. Rezende RB, Drachenberg CB, Kumar D, et al. Differential diagnosis between monomorphic clear cell adenocarcinoma of salivary glands and renal (clear) cell carcinoma. Am J Surg Pathol 1999; 23: 1532-8.

5. Yao M, Tabuchi H, Nagashima Y, et al. Gene expression analysis of renal carcinoma: adipose differentiation-related protein as a potential diagnostic and prognostic biomarker for clear-cell renal carcinoma. J Pathol 2005; 205: 377-87.

6. Yao M, Huang Y, Shioi K, et al. Expression of adipose differentiationrelated protein: a predictor of cancer-specific survival in clear cell renal carcinoma. Clin Cancer Res 2007; 13: 152-60.

7. Tun HW, Marlow LA, von Roemeling CA, et al. Pathway signature and cellular differentiation in clear cell renal cell carcinoma. PLoS One 2010; 5: e10696.

8. Hasenpusch-Theil K, Chadwick BP, Theil T, Heath SK, Wilkinson DG, Frischauf AM. PHF2, a novel PHD finger gene located on human 
chromosome 9q22. Mamm Genome 1999; 10: 294-8.

9. Okuno $\mathrm{Y}$, Ohtake F, Igarashi $\mathrm{K}$, et al. Epigenetic regulation of adipogenesis by PHF2 histone demethylase. Diabetes 2013; 62: 1426-34.

10. Okuno $Y$, Inoue K, Imai Y. Novel insights into histone modifiers in adipogenesis. Adipocyte 2013; 2: 285-8.

11. Baba A, Ohtake F, Okuno Y, et al. PKA-dependent regulation of the histone lysine demethylase complex PHF2-ARID5B. Nat Cell Biol 2011; 13: 668-75.

12. Stender JD, Pascual G, Liu W, et al. Control of proinflammatory gene programs by regulated trimethylation and demethylation of histone H4K20. Mol Cell 2012; 48: 28-38.

13. Sinha S, Singh RK, Alam N, Roy A, Roychoudhury S, Panda CK. Alterations in candidate genes PHF2, FANCC, PTCH1 and XPA at chromosomal 9q22.3 region: pathological significance in early- and late-onset breast carcinoma. Mol Cancer 2008; 7: 84.

14. Sun LL, Sun XX, Xu XE, et al. Overexpression of Jumonji AT-rich interactive domain $1 \mathrm{~B}$ and $\mathrm{PHD}$ finger protein 2 is involved in the progression of esophageal squamous cell carcinoma. Acta Histochem 2013; 115: 56-62.

15. Ghosh A, Maiti GP, Bandopadhyay MN, et al. Inactivation of $9 \mathrm{q} 22.3$ tumor suppressor genes predict outcome for patients with head and neck squamous cell carcinoma. Anticancer Res 2013; 33: 1215-20.

16. Lee KH, Park JW, Sung HS, et al. PHF2 histone demethylase acts as a tumor suppressor in association with p53 in cancer. Oncogene 2015; 34: 2897-909.

17. Edge SB, Byrd DR, Compton CC, Fritz AG, Greene FL, Trotti A 3rd. AJCC cancer staging manual. 7th ed. New York: Springer, 2010; 479-90.
18. Musri MM, Carmona MC, Hanzu FA, Kaliman P, Gomis R, Párrizas M. Histone demethylase LSD1 regulates adipogenesis. J Biol Chem 2010; 285: 30034-41.

19. Brasaemle DL, Barber T, Wolins NE, Serrero G, Blanchette-Mackie EJ, Londos C. Adipose differentiation-related protein is an ubiquitously expressed lipid storage droplet-associated protein. J Lipid Res 1997; 38: 2249-63.

20. Gao J, Serrero G. Adipose differentiation related protein (ADRP) expressed in transfected COS-7 cells selectively stimulates long chain fatty acid uptake. J Biol Chem 1999; 274: 16825-30.

21. Thoenes W, Störkel S, Rumpelt HJ. Histopathology and classification of renal cell tumors (adenomas, oncocytomas and carcinomas): the basic cytological and histopathological elements and their use for diagnostics. Pathol Res Pract 1986; 181: 125-43.

22. Tripathi A, Dasgupta S, Roy A, et al. Sequential deletions in both arms of chromosome 9 are associated with the development of head and neck squamous cell carcinoma in Indian patients. J Exp Clin Cancer Res 2003; 22: 289-97.

23. Baytekin F, Tuna B, Mungan U, Aslan G, Yorukoglu K. Significance of P-glycoprotein, p53, and survivin expression in renal cell carcinoma. Urol Oncol 2011; 29: 502-7.

24. Noon AP, Polanski R, El-Fert AY, et al. Combined p53 and MDM2 biomarker analysis shows a unique pattern of expression associated with poor prognosis in patients with renal cell carcinoma undergoing radical nephrectomy. BJU Int 2012; 109: 1250-7.

25. Noon AP, Vlatkovic N, Polanski R, et al. p53 and MDM2 in renal cell carcinoma: biomarkers for disease progression and future therapeutic targets? Cancer 2010; 116: 780-90. 